\title{
Pengaruh Kualitas Pelayanan Pembelian Tiket Bioskop Online Tix Id Terhadap Loyalitas Pelanggan
}

\author{
Gilang Ramadhan Martha \& Muhammad Gafar Yoedtadi \\ rikudogilang@gmail.com; gafary@fikom.untar.ac.id \\ Fakultas Ilmu Komunikasi Universitas Tarumanagara
}

\begin{abstract}
The existence of the smartphone is usual to use today, so that everyone should have as a supporting tool in finding information. Smartphones are increasingly diverse functions even easier for users on the move, one example is the emergence of buying and selling online applications. TIX ID is one of the applications that support the purchase of cinema tickets online. This study aims to determine the effect of service quality cinema tickets online TIX ID on customer loyalty. The method used is quantitative method. The number of respondents used in this study were 85 students of the Faculty of Computer Science Information Systems Mercu Buana University. Analysis of data using Test Validity, Test The reliability, normality test, Correlation, Regression Analysis test, and test hypotheses. Based on this research, it was found that there is significant influence and strong relationship between the quality of service on customer loyalty.
\end{abstract}

Keywords: customer loyalty, purchase tickets online cinema, quality of service

\begin{abstract}
Abstrak
Keberadaan smartphone merupakan hal yang lazim untuk digunakan saat ini, sehingga semua orang harus memilikinya sebagai alat penunjang dalam mencari informasi. Fungsi smartphone yang kian beragam semakin memudahkan penggunanya dalam beraktivitas, salah satu contohnya adalah munculnya berbagai aplikasi jual-beli online. Tix Id adalah salah satu aplikasi yang mendukung pembelian tiket bioskop secara online. Penelitian ini bertujuan untuk mengetahui pengaruh kualitas pelayanan pembelian tiket bioskop online Tix Id terhadap loyalitas pelanggan. Metode penelitian yang digunakan adalah metode kuantitatif. Jumlah responden yang digunakan dalam penelitian ini sebanyak 85 orang mahasiswa/ mahasiswi Sistem Informasi Fakultas Ilmu Komputer Universitas Mercu Buana Jakarta. Analisis data menggunakan Uji Validitas, Uji Reliabilitas, Uji Normalitas, Uji Korelasi, Uji Analisis Regresi, dan Uji Hipotesis. Berdasarkan hasil penelitian, ditemukan bahwa terdapat pengaruh yang signifikan dan hubungan yang kuat antara kualitas pelayanan pada loyalitas pelanggan.
\end{abstract}

Kata Kunci: kualitas Pelayanan; loyalitas pelanggan; pembelian tiket bioskop online.

\section{Pendahuluan}

Smartphone merupakan penghubung bagi pengguna internet di Indonesia untuk berselancar pada dunia maya. Di era serba modern sekarang ini keberadaan smartphone merupakan hal yang sangat wajib sebagai alat penunjang dalam mencari informasi. Seiring berkembangnya teknologi, fungsi smartphone semakin beragam. Tidak hanya digunakan untuk berkomunikasi, namun dapat digunakan untuk hiburan, bersosialisasi, bekerja dan bahkan dapat digunakan untuk mengembangkan hobi.

Penggunaan internet di Indonesia tumbuh dengan pesat dan menyebar hingga ke dunia bisnis, salah satu hasil perkembangan teknologi adalah munculnya aplikasiaplikasi jual beli berbasis online, (Wijaya \& Oktavianti, 2018). Hadirnya aplikasi 
Gojek dan Tokopedia dinilai sangat membantu masyarakat dalam kegiatan sehari-hari. Selain aplikasi-aplikasi tersebut, yang mulai diminati saat ini adalah aplikasi pembelian tiket bioskop online. Hadirnya aplikasi Tix Id membawa pengaruh besar terhadap cara pembelian tiket bioskop, yang semula harus mengantri panjang namun saat ini tiket bioskop dapat dibeli hanya melalui smartphone kapan dan dimanapun dengan sangat mudah dan praktis. Tix Id adalah sebuah aplikasi yang menawarkan layanan pembelian tiket bioskop online yang dirilis pada 21 Maret 2018. Aplikasi ini diciptakan oleh PT. Nusantara Elang Sejahtera yang telah berdiri sejak tahun 1985. Aplikasi Tix.Id dapat diunduh secara gratis di Google Play store dan App Store. Berdasarkan latar belakang diatas, maka penulis tertarik untuk melakukan penelitian dengan judul "Pengaruh Kualitas Pelayanan Pembelian Tiket Bioskop Online Tix Id Terhadap Loyalitas Pelanggan”.

Penelitian ini bertujuan untuk mengetahui apakah ada pengaruh antara kualitas pelayanan pembelian tiket bioskop online Tix Id terhadap loyalitas pelanggan dan seberapa besar pengaruh tersebut. Penelitian ini berhubungan dengan komunikasi pemasaran, Menurut Mahmud (2010:63), komunikasi pemasaran adalah hal penting untuk pemasaran serta penentu berhasilnya pemasaran. Dengan variabel x kualitas pelayanan, Menurut Tjiptono (2011), menyatakan bahwa kualitas pelayanan adalah nilai kualitas yang diinginkan dan pengendalian atas nilai kualitas tersebut untuk memenuhi keinginan pelanggan. Menurut Hasan (2008), loyalitas pelanggan diartikan sebagai orang yang membeli, terlebih yang membeli secara berulang-ulang.

\section{Metode Penelitian}

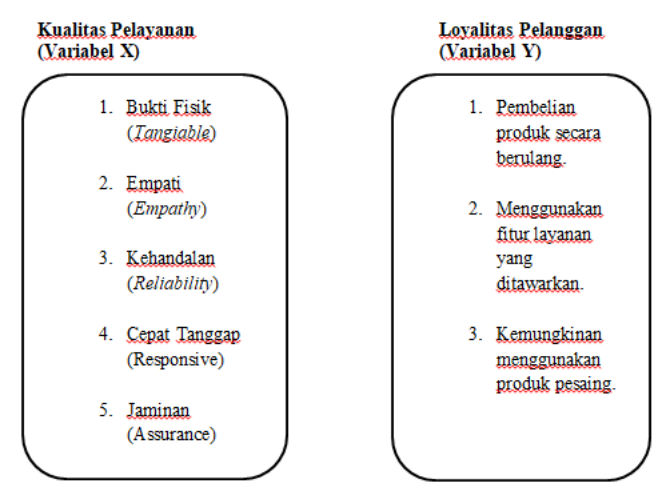

Gambar 1: Kerangka Pemikiran

Metode yang digunakan dalam penelitian ini adalah dengan pendekatan kuantitatif. Teknik pengumpulan data yang digunakan dalam penelitian ini adalah dengan kuesioner. Kuesioner ini berisi pertanyaan tentang Tix Id yang disebar kepada 85 orang mahasiswa/mahasiswi Sistem Informasi Fakultas Ilmu Komputer Universitas Mercu Buana Jakarta. Variabel bebas dalam penelitian ini adalah kualitas pelayanan TIX ID, dan variabel terikatnya adalah loyalitas pelanggan. Pengukuran data menggunakan skala Likert. Skala Likert biasa digunakan untuk mengukur sikap individu terhadap suatu objek sikap. Objek sikap ini biasanya sudah ditentukan secara spesifik dan sistematik oleh peneliti.

Indikator-indikator dari variabel merupakan tolak ukur dalam membuat pertanyaan yang harus diisi responden. Setiap pertanyaan atau pernyataan dihubungkan dengan jawaban yang berupa dukungan atau pernyataan sikap yang 
Gilang Ramadhan Martha: Pengaruh Kualitas Pelayanan Pembelian Tiket Bioskop Online Tix Id Terhadap Loyalitas Pelanggan

diungkapkan dengan kata-kata: (5) Sangat Setuju (ST),(4) Setuju (S), (3) Netral (N), (2) Tidak Setuju (TS), (1) Sangat Tidak Setuju (STS).

Pada penelitian ini yang menjadi populasi penelitian adalah mahasiswa atau mahasiswi Sistem Informasi Fakultas Ilmu Komputer di Universitas Mercu Buana Jakarta. Peneliti mengambil sampel penelitian sebanyak 85 responden dengan teknik pengambilan sampel menggunakan rumus Slovin. Teknik analisis data yang digunakan pada penelitian ini adalah analisis deskriptif, Uji Validitas, Uji Reliabilitas, Uji Normalitas, Uji Korelasi, Uji Regresi dan Uji Hipotesis.

\section{Analisis dan Pembahasan}

Tabel 1: Hasil Uji Validitas

\begin{tabular}{cllc}
\hline \multirow{2}{*}{ Variabel } & \multicolumn{1}{c}{ Butir Indikator } & $\begin{array}{c}\text { Corrected } \\
\text { Item Total } \\
\text { Correlatio } \\
\text { n }\end{array}$ & $\begin{array}{c}\text { Keteranga } \\
\mathbf{n}\end{array}$ \\
\hline \multirow{4}{*}{$\begin{array}{c}\text { Kualitay } \\
\text { Pelayana } \\
\text { n }\end{array}$} & Kualitas Pelayanan 1 & 0,472 & Valid \\
\cline { 2 - 4 } & Kualitas Pelayanan 2 & 0,606 & Valid \\
\cline { 2 - 4 } & Kualitas Pelayanan 3 & 0,534 & Valid \\
\cline { 2 - 4 } & Kualitas Pelayanan 4 & 0,321 & Valid \\
\cline { 2 - 4 } & Kualitas Pelayanan 5 & 0,586 & Valid \\
\cline { 2 - 4 } & Kualitas Pelayanan 6 & 0,604 & Valid \\
\cline { 2 - 4 } & Kualitas Pelayananan 7 & 0,542 & Valid \\
\cline { 2 - 4 } & Kualitas Pelayanan 9 & 0,495 & Valid \\
\cline { 2 - 4 } & Loyalitas Pelanggan 1 & 0,528 & Valid \\
\cline { 2 - 4 } $\begin{array}{c}\text { Loyalitas Pelanggan 2 } \\
\text { Pelangga } \\
\text { n }\end{array}$ & Loyalitas Pelanggan 3 & 0,574 & Valid \\
\cline { 2 - 4 } & Loyalitas Pelanggan 4 & 0,576 & Valid \\
\cline { 2 - 4 } & Loyalitas Pelanggan 5 & 0,517 & Valid \\
\cline { 2 - 4 } & Loyalitas Pelanggan 6 & 0,532 & Valid \\
\hline
\end{tabular}

(Sumber: Data Primer, Diolah dengan SPSS, 2019)

Dari hasil uji validasi di atas diketahui bahwa pertanyaan dari seluruh variabel dinyatakan valid. Hal ini dikarenakan pertanyaan variabel memiliki nilai korelasi diatas 0,2 .

Tabel 2: Uji Reliabilitas

\begin{tabular}{ccc}
\hline Variabel & Cronbach's Alpha & Keterangan \\
\hline Kualitas Pelayanan & 0,819 & Reliable \\
\hline Loyalitas Pelanggan & 0,759 & Reliable \\
\hline
\end{tabular}

(Sumber: Data Primer, Diolah dengan SPSS, 2019)

Tabel diatas menunjukan bahwa hasil uji reabilitas dari variabel kualitas pelayanan dan loyalitas pelanggan dapat dinyatakan reliabel semua, karena memiliki angka yang lebih besar dari 0,600. Dapat dilihat bahwa variabel kualitas pelayanan memiliki nilai cronbach's alpha sebesar 0,819 dan variabel loyalitas pelanggan memiliki nilai sebesar 0,759 . 


\section{Uji Normalitas}

Hipotesis yang telah dirumuskan akan diuji dengan statistik parametris, antara lain dengan menggunakan t-test untuk satu sampel, korelasi dan regresi, analisis varian dan t-test untuk satu sampel. Penggunaan statistik parametris mensyaratkan bahwa data setiap variabel yang akan dianalisis harus berdistribusi normal. Oleh karena itu sebelum pengujian hipotesis dilakukan, maka terlebih dahulu akan dilakukan pengujian normalitas data, Sugiono (2008).

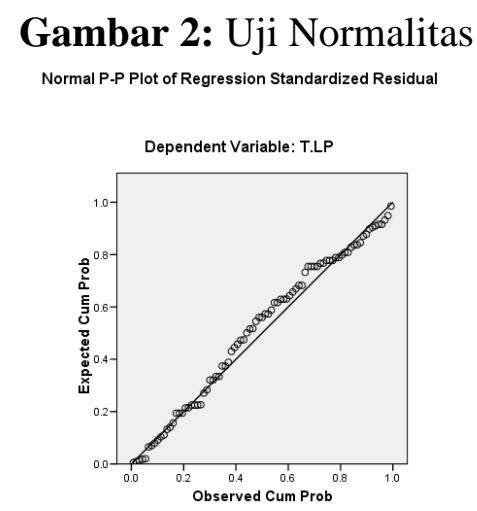

(Sumber: Data Primer, Diolah dengan SPSS)

Berdasarkan gambar grafik di atas, menunjukan data yang menyebar di sekitar garis diagonal dengan arah hubungan yang positif dan mengikuti arah garis diagonal. Grafik ini menandakan bahwa data berdistribusi dengan normal, karena semakin dekat suatu data dengan garis lurus, artinya pendistribusiannya semakin normal.

\section{Uji Korelasi}

Korelasi dan regresi mempunyai hubungan yang erat karena setiap regresi dipastikan terdapat korelasi. Tetapi tidak selalu korelasi dilanjutkan dengan regresi. Dari hasil analisis korelasi sederhana antara kualitas pelayanan dengan loyalitas pelanggan adalah. Hal ini menunjukan bahwa terjadi hubungan yang cukup berarti antara kualitas pelayanan dengan loyalitas pelanggan.

Tabel 3: Uji Korelasi Correlations

\begin{tabular}{|ll|r|r|}
\hline & \multicolumn{1}{|c|}{ T.KP } & \multicolumn{1}{c|}{ T.LP } \\
\hline T.KP & Pearson Correlation & 1 &, $717\left(^{* *}\right)$ \\
& Sig. (2-tailed) & & 000 \\
N & 85 & 85 \\
T.LP & Pearson Correlation &, $717\left(^{* *}\right)$ & 1 \\
& Sig. (2-tailed) &, 000 & \\
N & 85 & 85 \\
\hline \multirow{2}{*}{ ** Correlation is significant at the 0.01 level (2-tailed). }
\end{tabular}

(Sumber: Data Primer, Diolah dengan SPSS, 2019)

Data di atas menjelaskan jika variabel $\mathrm{X}$ mendapatkan nilai 0,717 maka nilai variabel Y akan mendapatkan nilai yang sama. Nilai (r) sebesar 0,717 menunjukan hubungan yang terjadi antara variabel $\mathrm{X}$ dan variabel $\mathrm{Y}$ yaitu kuat. 
Gilang Ramadhan Martha: Pengaruh Kualitas Pelayanan Pembelian Tiket Bioskop Online Tix Id Terhadap Loyalitas Pelanggan

\section{Uji Analisis Regresi}

Analisis regresi digunakan pada penelitian yang memiliki korelasi antara variabel satu dengan variabel lainnya. Dalam penelitian ini menggunakan bantuan aplikasi SPSS yang menghasilkan data pada tabel di bawah ini:

Tabel 4: Hasil Uji Analisis Regresi

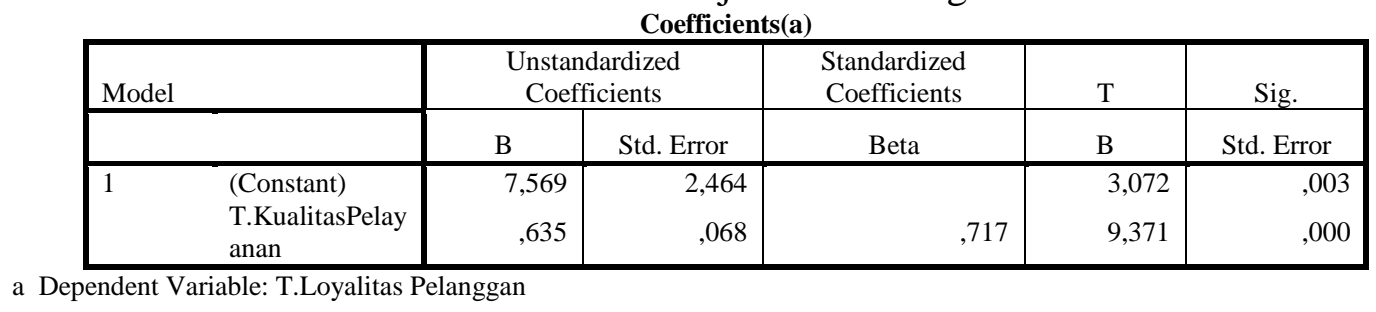

(Sumber: Data Primer, Diolah dengan SPSS, 2019) berikut:

Dari hasil tabel di atas, dapat dilihat persamaan regresi sederhana yaitu sebagai

$$
\begin{aligned}
& \text { Rumus Regresi Linear Sederhana } \\
& Y=a+b . X
\end{aligned}
$$

Dimana Y adalah Loyalitas Pelanggan dan X adalah Kualitas Pelayanan. Berdasarkan persamaan regresi diatas dapat disimpulkan bahwa nilai konstan sebesar 7,569, yang berarti nilai variabel $\mathrm{Y}$ (loyalitas pelanggan) adalah 7,569, jika nilai variabel $X$ (kualitas pelayanan) adalah 0,000. Dan jika ada kenaikan dari setiap variabel X (kualitas pelayanan) maka akan mempengaruhi 0,635 atau 63,5\% terhadap variabel Y (loyalitas pelanggan). Sisanya sebesar 36,5\% dipengaruhi oleh faktor lain yang tidak ada di dalam penelitian ini seperti tampilan aplikasi, kualitas server, iklan yang ditampilkan, dan faktor-faktor lainnya. Dengan hasil analisis ini, diketahui bahwa persamaan untuk studi ini adalah:

$$
Y=7,569+0,63,5 X
$$

\section{Uji Hipotesis}

Pada penelitian ini digunakan uji statistik untuk menguji hipotesis mana yang akan diambil. Uji t berguna untuk mengetahui apakah ada atau tidaknya pengaruh yang signifikan dari variabel bebas (kualitas pelayanan) terhadap variabel terikat (loyalitas

\begin{tabular}{|c|c|c|c|c|c|c|}
\hline \multicolumn{2}{|c|}{ Model } & Sum of Squares & Df & Mean Square & $\mathrm{F}$ & Sig. \\
\hline \multirow[t]{3}{*}{1} & Regression & 555,856 & 1 & \multirow{3}{*}{$\begin{array}{r}555,856 \\
6,330\end{array}$} & \multirow[t]{3}{*}{87,817} & \multirow[t]{3}{*}{,000(a) } \\
\hline & Residual & 525,367 & 83 & & & \\
\hline & Total & 1081,224 & 84 & & & \\
\hline
\end{tabular}
pelanggan).

Tabel 4.26 Anova X Terhadap Y

(Sumber: Data Primer, Diolah dengan SPSS, 2019) 
Maka dengan hasil Sig $=0,000<0,05$ maka $\mathrm{H}_{0}$ ditolak dalam penelitian ini. Hal ini menunjukan bahwa variabel kualitas pelayanan (X) terhadap variabel loyalitas pelanggan (Y) pada TIX ID untuk mahasiswa/ mahasiswi Sistem Informasi Fakultas Ilmu Komputer Universitas Mercu Buana Jakarta memiliki pengaruh yang signifikan.

\section{Kesimpulan}

Berdasarkan hasil penelitian, mendapatkan hasil bahwa terdapat pengaruh antara variabel kualitas pelayanan (X) yang terdiri dari bukti fisik (tangible), empati (empathy), kehandalan (reliability), cepat tanggap (responsive), dan jaminan (assurance) terhadap variabel loyalitas pelanggan (Y) yang terdiri dari kesediaan menggunakan produk secara berulang, kemauan menggunakan fitur-fitur yang disediakan dan kemungkinan menggunakan produk pesaing.

Berdasarkan hasil penelitian ini ditemukan bahwa kualitas pelayanan TIX ID sangat dominan pada empati (empathy) dan kehandalan (reliability). Sehingga menimbulkan loyalitas pelanggan untuk menggunakan produk secara berulang. Hal ini dikarenakan konsumen merasa dimudahkan dalam menonton bioskop karena adanya harga promo dari TIX ID, dan dimanjakan dengan proses pembayaran yang mudah, maka muncul kepuasan yang melahirkan sebuah loyalitas pelanggan terhadap TIX ID untuk menggunakannya secara berulang kali.

\section{Ucapan Terimakasih}

Peneliti memanjatkan puji syukur kepada Allah SWT karena atas rahmatNya peneliti dapat menyelesaikan jurnal ini. Peneliti juga ingin mengucapkan terima kasih kepada seluruh teman-teman yang telah memberikan dukungannya kepada peneliti sehingga peneliti dapat menyelesaikan jurnal ini sesuai dengan yang diharapkan.

\section{Daftar Pustaka}

Hasan. (2008). Marketing. Malang: Bayu Media.

Mahmud, A. (n.d.). Tes Profesi STAN. Malang: BookST.

Sugiyono. (2008). Metode Penelitian Kuantitatif, Kualitatif, dan R\&D. Bandung: Alfabeta.

Sugiyono. (2014). Metode Penelitian Kombinasi (Mixed Methods). Bandung: Alfabeta.

Tjiptono, F. (2011). Pemasaran Jasa. Malang: Bayu Media.

Tjiptono, F., \& Chandra, G. (2012). Pemasaran Strategik. Yogyakarta: Andi.

Wijaya, S., \& Oktavianti, R. (2018). Pengaruh Kualitas Pelayanan Belanja Daring terhadap Corporate Image (Studi Pada Pelanggan Perusahaan JD.id). Prologia, Vol. 2. 